\title{
Induction Heating and Healing Behaviors of Asphalt Concretes Doped with Different Conductive Additives
}

\author{
Hechuan Li, ${ }^{1}$ Jianying Yu, ${ }^{1}$ Quantao Liu $\mathbb{D},{ }^{1}$ Yuanyuan Li, ${ }^{1}$ Yaqi $\mathrm{Wu},{ }^{2}$ and Haiqin Xu${ }^{1}$ \\ ${ }^{1}$ State Key Laboratory of Silicate Materials for Architectures, Wuhan University of Technology, Wuhan 430070, China \\ ${ }^{2}$ China University of Geosciences (Wuhan), Wuhan 430074, China \\ Correspondence should be addressed to Quantao Liu; liuqt@whut.edu.cn
}

Received 30 November 2018; Revised 25 February 2019; Accepted 7 March 2019; Published 15 April 2019

Academic Editor: Pramod Koshy

Copyright () 2019 Hechuan Li et al. This is an open access article distributed under the Creative Commons Attribution License, which permits unrestricted use, distribution, and reproduction in any medium, provided the original work is properly cited.

\begin{abstract}
It is consensual that the self-healing property of asphalt concrete can repair the damage inside it during high temperature and rest period. In order to not affect the traffic, the rest period of asphalt pavement is very short and uncontrollable; so, it is necessary to obtain enough high temperature in a limited time to achieve higher healing efficiency of asphalt concrete. The purpose of this paper is to study the induction heating efficiency and healing behaviors of asphalt concretes doped with different conductive additives. Steel fiber, steel grit, and steel slag were added to asphalt mixtures as conductive additives to prepare induction healing asphalt concretes. The steel grit and steel slag were added to replace the aggregates of corresponding particle size by equal volume to ensure the consistency of asphalt concrete volume, which can avoid degrading the performance of asphalt concrete due to the change of porosity. The induction heating efficiency and healing rate of asphalt concrete were quantified by infrared camera and three-point bending-healing experiment, respectively. The results showed that the thermal properties of asphalt concrete changed with the addition of different conductive additives. The asphalt concrete with steel fiber had the best induction heating property. While steel slag had extremely weak induction heating speed, the better thermal insulation property of the asphalt concrete with steel slag resulted in a higher induction healing rate. It was suggested to add steel slag to induction healing asphalt concrete to improve the healing rate.
\end{abstract}

\section{Introduction}

Asphalt concrete pavement has attracted more and more attention because of its excellent service performance [1-5]. However, due to environmental and human factors, such as temperature [6], moisture [7], ultraviolet rays [8], and heavy load [9], it is often difficult for the service life of the asphalt concrete pavement to reach the design life. Macroscopic distresses, such as potholes, cracks, and ruts, are often caused by microdamage inside asphalt concrete $[10,11]$. Induction heating is a new maintenance technology to repair microcracks in asphalt concrete to avoid macroscopic distresses [12-14]. Similar to other self-healing materials, asphalt concrete can repair the damage autonomously. Asphalt concrete has a potential to restore its stiffness and strength during rest periods. However, this internal restoration is very slow; so, this process needs to be speeded up in some way. Liu et al. first published the work on self-healing asphalt concrete with steel fiber in 2011 [15], and after that, more and more research has been carried out in this direction. Among most of those previous works, temperature is widely considered as a key factor for induction heating efficiency of asphalt concrete, and a higher induction healing rate is expected to be obtained during the road rest period. But at the moment, the most common way is to add conductive additives to asphalt binder $[16,17]$. A major advantage of this method is that the energy is generated from the asphalt mortar and does not directly act on the aggregate, with the coarse aggregate being not subjected to excessive temperature stress due to excessive temperature change. However, it will take longer time to transfer the temperature from the asphalt binder to the whole asphalt concrete, thus 
prolonging the induction healing time. Since asphalt concrete has about $95 \%$ aggregate, if conductive additives can be used to replace some aggregates without affecting the service performance of asphalt concrete, it may obtain better induction heating efficiency.

Steel slag is one of the industrial wastes, which makes up a portion of more than $10 \%$ of raw steel output $[18,19]$, and a large amount of steel slag will be produced in the steelmaking process. The mineral composition of steel slag includes calcium silicate $\left(\mathrm{C}_{2} \mathrm{~S}\right)$, calcium ferrite $\left(\mathrm{C}_{4} \mathrm{AF}, \mathrm{C}_{2} \mathrm{~F}\right)$, and calcium aluminate $\left(\mathrm{C}_{3} \mathrm{~A}, \mathrm{C}_{12} \mathrm{~A}_{7}\right)$ [20]. Steel slag has been applied in many fields, such as the production of cement and concrete $[18,20]$, purification engineering $[21,22]$, and road construction [23]. However, little research has been done on the application of steel slag in induction healing asphalt concrete. On the one hand, steel slag has excellent thermal insulation; on the other hand, the energy generated by induction heating needs to be long standingly preserved in order to achieve an adequate repair of asphalt concrete. Therefore, the application of steel slag in induction healing asphalt concrete can not only better induce healing performance but also save resources.

Induction healing asphalt concrete has been paid more and more attention because of its great potential, such as prolonging the pavement service life $[12,13,15,16]$ and the application in melting snow and ice [24]. It is one of the research directions of the new generation smart pavement in the world at present. Steel slag, as a kind of solid waste, has been paid equal attention to its recycling and reuse. Its excellent performance has made it possible to use as pavement building material. At the same time, the excellent thermal properties of steel slag make it perfectly fit for induction healing asphalt concrete. The combination of them can not only improve the performance of induction healing asphalt concrete but also provide a new idea for the reuse of steel slag.

This study aims to explore the induction heating efficiency and healing rate of asphalt concrete by using conductive additives, especially steel slag and steel grit, to partially replace aggregates of certain sizes. The study investigated the induction heating and healing behaviors of asphalt concretes doped with different conductive additives by an infrared camera and universal testing machine. The thermal property of different asphalt concretes was evaluated by the thermal constants analyzer (TPS 2500S, Hot Disk, Sweden). The chemical elements and oxide of steel slag were analyzed by X-ray fluorescence. In order to avoid the change of voids, the improved method (equal volume substitution method) was used to add steel grit and steel slag into asphalt concrete.

\section{Materials and Experiments}

2.1. Materials. Base asphalt graded 70 (penetration grade) obtained from Hubei Guochuang Hi-tech Material Co., Ltd of China was used in this paper. Steel wool fiber provided by Jiangsu Golden Torch Metal products Co., Ltd and steel grit provided by Ningbo Hongyang cleaning equipment Co., Ltd were used as the induction heating units for asphalt concrete, as shown in Figure 1. The properties of asphalt, steel wool fiber, and steel grit are shown in Table 1, while the impurity element composition of two conductive additives is shown in Table 2. During electromagnetic induction, the elements that can be heated are $\mathrm{Fe}, \mathrm{Co}$, and $\mathrm{Ni}$ [12]. The optimal content of fiber is $6 \%$ by the volume of asphalt according to the previous research [4]. Asphalt mixture with $6 \%$ steel wool fiber has best mechanical properties (highest strength and particle loss resistance) and quite high induction heating speed. The particle size of steel grit was $0.6-1.18 \mathrm{~mm}$, which replaced the fine aggregate of corresponding size by equal volume to avoid changing the void of asphalt concrete. The basalt aggregate, steel slag aggregate, and limestone filler were used in this study. Specifically, two sizes of steel slag $(4.75-9.5 \mathrm{~mm}$ and $9.5-13.2 \mathrm{~mm})$ were used to replace basalt to study the induction heating characteristics and healing behavior of steel slag induction healing asphalt concrete. According to [25], the properties of steel slag were evaluated, as shown in Table 3. All properties meet the requirements of the code for steel slag aggregate for asphalt pavement. Although the water absorption rate was on the high side, it did not exceed the technical requirements too much.

\subsection{Specimen Preparation}

2.2.1. Asphalt Concrete. In order to study the induction heating efficiency and healing behaviors, six kinds of asphalt concretes were designed. Firstly, AC-13 basalt asphalt concrete was designed according to the Marshall design method, and the asphalt-aggregate ratio was $4.7 \%$. The aggregate gradations and grading curves of asphalt concrete are shown in Figure 2. This kind of asphalt concrete was named BA. Secondly, the asphalt concrete was doped with $6 \%$ steel wool fiber by the volume of asphalt in BA, which was named FA. Thirdly, on the basis of FA, two sizes of steel slag aggregates $(4.75-9.5 \mathrm{~mm}$ and $9.5-13.2 \mathrm{~mm}$ ) were used to replace basalt aggregates to generate new asphalt concrete, which was named FSA. Fourthly, also on the basis of FA, steel grit $(0.6-1.18 \mathrm{~mm})$ was used to replace basalt aggregates to design a new asphalt concrete named FGA. Fifthly, the above steel grit and steel slag simultaneously replaced basalt aggregates to obtain GSA. Finally, FGSA was obtained by adding steel fiber into BA and replacing basalt aggregate with steel grit and steel slag. The list of different asphalt concretes ingredients is given in Table 4 . It should be pointed out that steel slag and steel grit replaced basalt aggregates by the same volume, which avoids changing air void content of asphalt concrete for the future researches. In the three-point bending test and induction heating test, the specimens were rectangular beam with a notch cut by rutting board in a size of $85 \mathrm{~mm} \times 50 \mathrm{~mm} \times 10 \mathrm{~mm}$, as shown in Figure 3 .

2.3. Thermal Property Test. The thermal conductivity of steel fiber, steel grit, and steel slag is very good, which is different from that of aggregate, asphalt, and filler in asphalt concrete; so, it is necessary to study their influence on the thermal constants of asphalt concrete as a whole. The thermal 


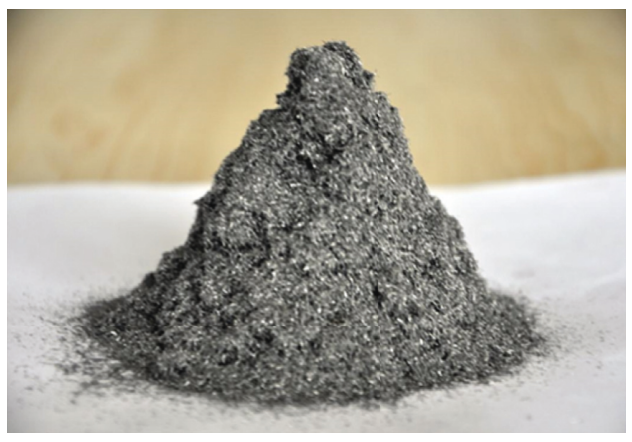

(a)

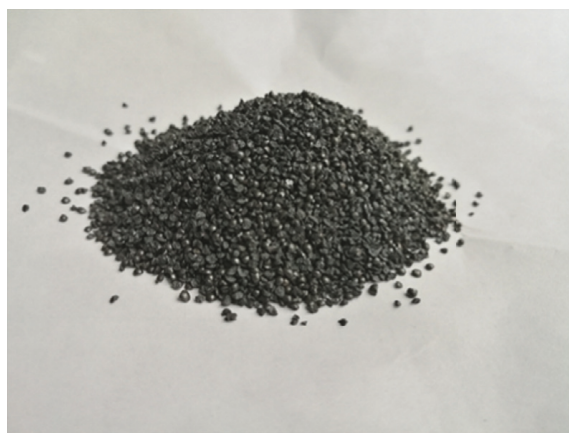

(b)

Figure 1: Steel wool fiber (a) and steel grit (b).

TABLE 1: The properties of asphalt, steel wool fiber, and steel grit.

\begin{tabular}{lccc}
\hline Materials & Properties & Values & Specifications \\
\hline \multirow{4}{*}{ Asphalt } & Penetration $\left(25^{\circ} \mathrm{C}, 100 \mathrm{~g}, 5 \mathrm{~s}, 0.1 \mathrm{~mm}\right)$ & 68 & $60-80$ \\
& Ductility $\left(15^{\circ} \mathrm{C}, \mathrm{cm}\right)$ & $>100$ & 47.5 \\
100 & 47 \\
& Softening point $\left({ }^{\circ} \mathrm{C}\right)$ & 1.034 & - \\
\hline \multirow{2}{*}{ Steel wool fiber } & Density $\left(\mathrm{g} / \mathrm{cm}^{3}\right)$ & 4.2 & - \\
& Average length $(\mathrm{mm})$ & $70-130$ & - \\
\hline \multirow{2}{*}{ Steel grit } & Equivalent diameter $(\mu \mathrm{m})$ & 7.8 & - \\
\hline
\end{tabular}

TABLE 2: The impurity element content of steel wool fiber and steel grit.

\begin{tabular}{|c|c|c|c|c|c|}
\hline \multirow{2}{*}{ Materials } & \multicolumn{5}{|c|}{ Chemical element } \\
\hline & $\mathrm{C}(\%)$ & Mn (\%) & $\mathrm{P}(\%)$ & S (\%) & Si $(\%)$ \\
\hline Steel wool fiber & $0.06-0.12$ & $0.8-1.2$ & $\leq 0.05$ & $\leq 0.05$ & $\leq 0.07$ \\
\hline Steel grit & $\leq 0.12$ & $\leq 2.00$ & $\leq 0.035$ & $\leq 0.03$ & $\leq 1.00$ \\
\hline
\end{tabular}

TABLE 3: Steel slag properties.

\begin{tabular}{lcccc}
\hline Test & Size $(\mathrm{mm})$ & Unit & Result & Technical requirement \\
\hline Apparent relative density & $9.5-13.2$ & - & 3.386 & $\geq 2.9$ \\
& $4.75-9.5$ & & 3.426 & $\leq 3$ \\
Water absorption & $9.5-13.2$ & $\%$ & 2.651 & $\leq 22$ \\
Crushing value & $4.75-9.5$ & $\%$ & 18.9 & $\leq 22$ \\
Los Angeles wear value & & $\%$ & 20.8 & $\leq 12$ \\
Needle flake content & & $\%$ & 4.2 & $\leq 4$ \\
Adhesion grade & & Level & 5 & $\leq 3$ \\
Soft stone content & & $\%$ & 0.4 & \\
& & &
\end{tabular}

constants of different asphalt concretes were measured using cylindrical samples with the size of $\Phi 101.6 \mathrm{~mm} \times 30 \mathrm{~mm}$. Different types of asphalt concrete Marshall specimens were prepared and cut to be tested at room temperature, as shown in Figure 4.

In the testing process, the particle size of the aggregate may be larger than the diameter of the Hot Disk probe, which leads to the difference of the test results. Therefore, in addition to increasing the parallel test data, the test deviation was reduced by changing the test area for the same test. The test areas of thermal constants are shown in Figure 5. The straight diameter of the sample is $101.6 \mathrm{~mm}$. The thermal constants were measured in 4 regions of the center, and the mean value was taken for 3 times for each part, that is, 12 times for each kind of asphalt concrete.

2.4. Induction Heating. Induction heating test, as shown in Figure 6, was divided into two parts: induction temperature and induction healing, where the distance from the surface 


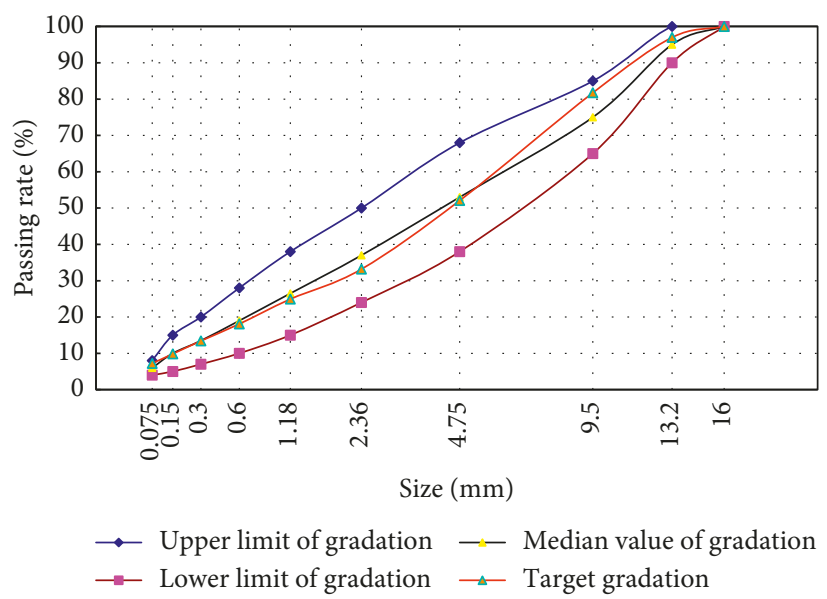

Figure 2: Grading curve of AC-13 basalt asphalt mixture.

TABLE 4: Composition of different kinds of asphalt concrete.

\begin{tabular}{lcc}
\hline AC-13 & Common & Component \\
\hline BA & & Particular \\
FA & & Steel fiber \\
FSA & Basalt, asphalt, limestone fillers, and air void & Steel fiber and steel slag \\
FGA & & Steel fiber and steel grit \\
GSA & Steel grit and steel slag \\
FGSA & & Steel fiber, steel grit, and steel slag \\
\hline
\end{tabular}

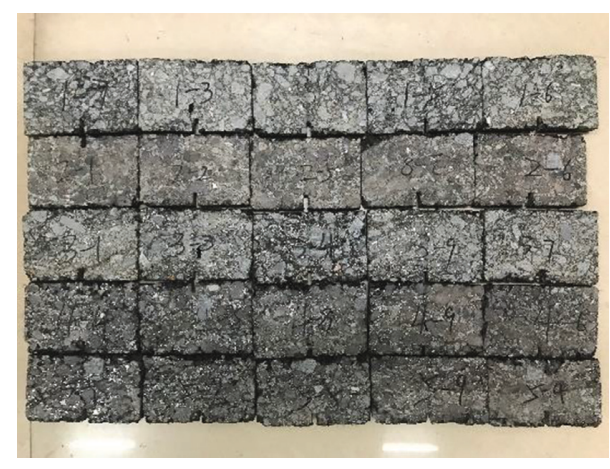

FIgURE 3: Asphalt concrete beams.

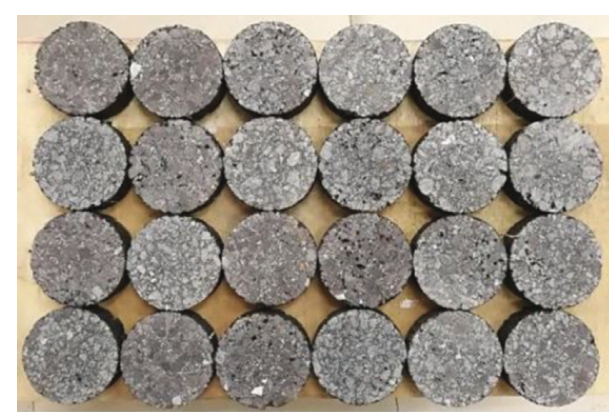

Figure 4: Thermal constant test samples.

of the sample to the coil was kept constantly at $10 \mathrm{~mm}$ [4]. The induction temperatures of both tests were monitored by an infrared camera with a resolution of $320 \times 240$ pixels. The frequency of the induction heating apparatus is always $123 \mathrm{kHz}$. For the induction temperature test, the output power was $7.6 \mathrm{~kW}$, while the power was $8.4 \mathrm{~kW}$ for the induction healing test. In order to obtain the best healing performance, the temperature of the induction healing test was set at $85^{\circ} \mathrm{C}$, which was verified in the previous research [26]. After each induction heating test, the samples had enough time to recover to ambient temperature. In this study, for Marshall samples, the temperature was the average temperature on the upper surface, while for other samples, the temperature was the average temperature of the sample as a whole.

2.5. Fracture and Healing Test. In this study, the three-point bending test was used to evaluate the induction healing performance of asphalt concrete. To avoid creeping, the experimental temperature was below $-20^{\circ} \mathrm{C}$, as shown in Figure 7 [27]. The load was applied at a rate of $5 \mathrm{~mm} / \mathrm{min}$, and the tests were stopped when the discharge curve did not change anymore. The average of ten parallel samples for each type of asphalt concrete was recorded.

The healing rate of asphalt concrete was defined as the relationship between the ultimate force $\left(F_{0}\right)$ of the beam during a three-point bending test and the ultimate force $\left(F_{t}\right)$ measured in the beam after some time healing, as shown in the following equation:

$$
H_{i}=\frac{F_{t}}{F_{0}} \times 100 \%
$$




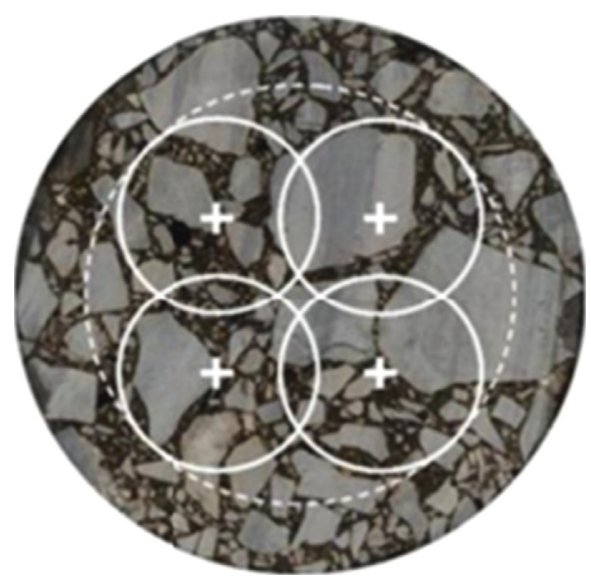

(a)

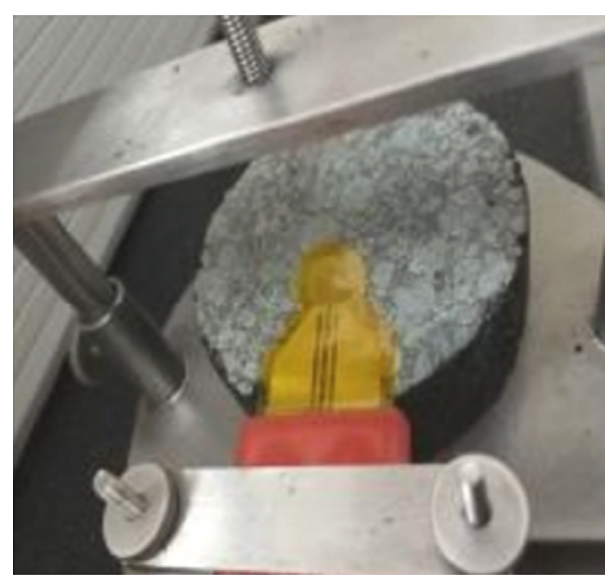

(b)

Figure 5: Thermal constant test region.

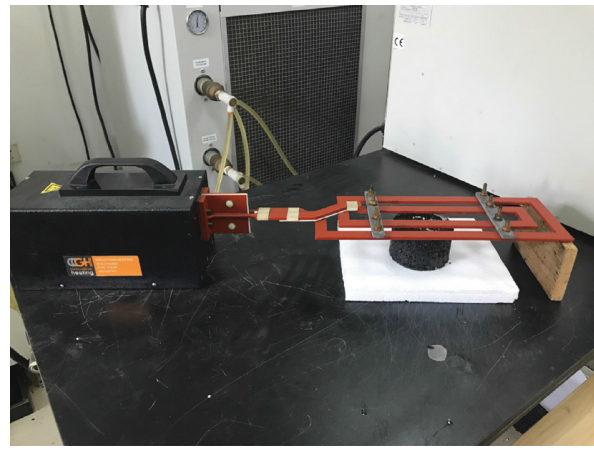

(a)

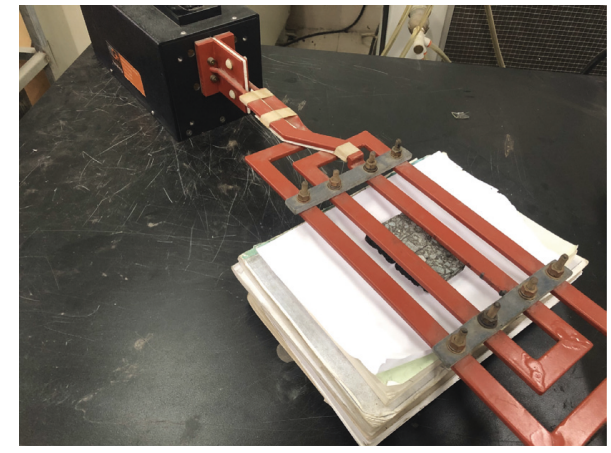

(b)

FIGURE 6: Experiment on (a) induction heating temperature and (b) induction healing.

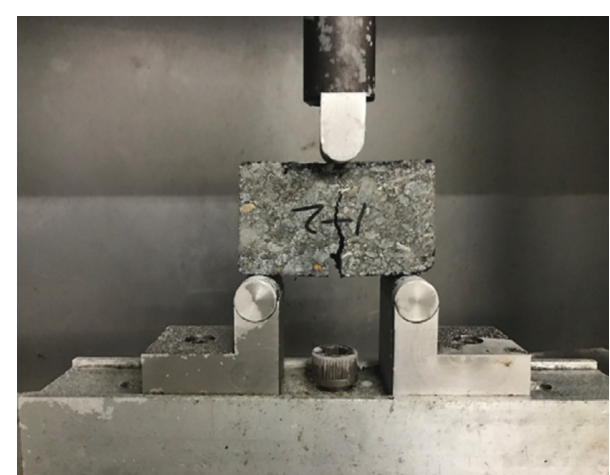

FIGURE 7: Three-point bending test.

\section{Results and Discussion}

3.1. Thermal Property Analysis. The difference of thermal conductivity will cause the difference of heat transfer in asphalt concrete. Therefore, the thermal conductivity of asphalt concrete is the factor that needs to be considered in the process of electromagnetic induction healing. The thermal conductivity of different materials varies greatly, among which metals are prominent. The larger the thermal conductivity, the faster the temperature transfers, and the more uniform the temperature distribution of the pavement is, which is more helpful to avoid the pavement distresses caused by the temperature change. But at the same time, the lower the rate of heat exchange between asphalt concrete and external environment, the more the beneficial to the healing of internal damage of asphalt concrete, because this can make asphalt concrete in the favorable healing temperature range for a longer time. So, our goal was to get an asphalt concrete that had a faster heat transfer rate inside and a slower heat exchange with the outside, which were evaluated by thermal diffusivity and specific heat.

Figure 8 shows the thermal diffusivity and specific heat of different asphalt concretes. From left to right, it was analyzed in turn how the thermal constants of asphalt concrete changed with the addition of steel fiber, steel grit, and steel slag. With the addition of steel fiber, asphalt concrete got higher thermal conductivity and smaller specific heat capacity, which was conducive to the rapid diffusion of internal temperature, but not conducive to the overall thermal insulation of asphalt concrete. Since the thermal conductivity of the metal was much greater than that of the other components of BA, and the specific heat was the opposite, it was easy to understand the change. The addition of steel grit also led to these changes, but the rate of change seemed to be greater, perhaps because steel grit 


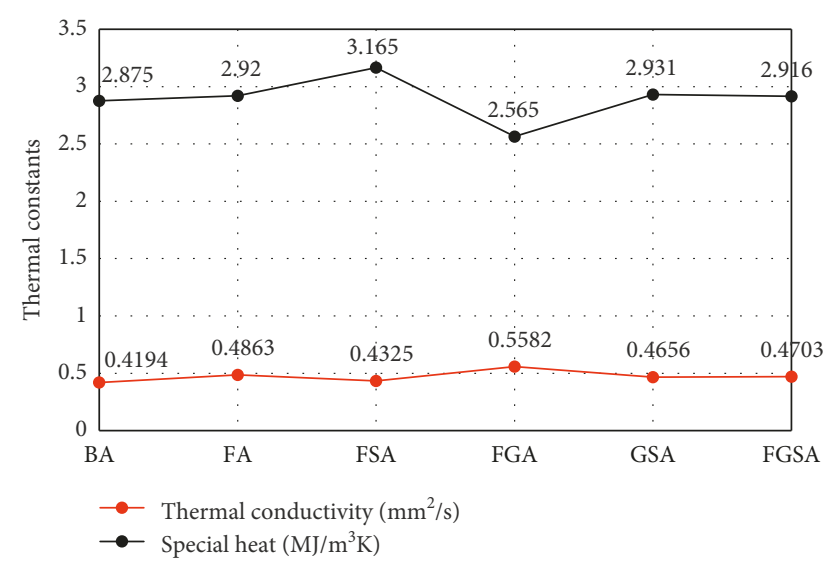

Figure 8: Thermal constants of different asphalt concretes.

replaced aggregates, rather than being wrapped in asphalt binders like steel fiber. Although steel slag could not be heated quickly by induction, which would be analyzed in the next section, the addition of steel slag seemed to increase the specific heat of asphalt concrete. For example, FSA reached to $3.165 \mathrm{MJ} / \mathrm{m}^{3} \mathrm{~K}$, which was more conducive to the insulation of asphalt concrete for better induction healing rate. This could be explained by the physicochemical characteristics of steel slag confirmed in the research by Chen et al. [1]. Although the limited metallic components and porous structure led slower induction heating rate of steel slag, its thermal insulation effect was better, and the purpose of using energy more reasonably was achieved. To sum up, although steel slag could not be effectively heated by induction, the asphalt concrete replaced traditional aggregates by steel slag can improve the efficiency of induction energy utilization, which helps to increase the induction healing rate.

3.2. Induction Heating Temperature Analysis. Figure 9 shows induction heating ability of steel fiber, steel grit, and steel slag after $5 \mathrm{~s}$ when the output power of the induction heating instrument is $8.3 \mathrm{~kW}$. It can be seen that the induction heating abilities of the three materials were in the order of steel fiber $>$ steel grit $>$ steel slag, where steel slag had extremely weak ability for induction heating. Through Wan et al. research [28], only iron and $\mathrm{Fe}_{3} \mathrm{O}_{4}$ can be heated by induction. The content of chemical elements and main oxides of steel slag were measured by XRF (PANalytical Axios, RIGAKU ZSX Priums), as shown in Table 5. From the table, it was found that all iron elements exist in the form of $\mathrm{Fe}_{2} \mathrm{O}_{3}$, which did not help much with induction heating.

Figure 10 shows average surface temperature of different kinds of asphalt concretes after induction heating for $60 \mathrm{~s}$, $120 \mathrm{~s}$, and $180 \mathrm{~s}$, and the $120 \mathrm{~s}$ infrared image is shown in Figure 11. In the light of the above study, the difference between the induction heating properties of the three materials was very clear. Because the induction heating ability of the steel fiber was better than that of the steel grit, it was observed that the induction heating ability of FSA was better than that of GSA. Therefore, the induction heating ability of conductive additives is paramount for induction heating asphalt concrete. FGA had the highest induction temperature, reaching $122.5^{\circ} \mathrm{C}$ after $180 \mathrm{~s}$. Comparing SA with FSA, also FGA with FGSA, it was found that, even though the internal inductive ability of asphalt concretes was the same, the temperature of asphalt concretes added with steel slag was lower than that of basalt after same induction time. This phenomenon verified the conclusion of the previous section. Although the energy generated by induction was the same, the specific heat capacity of asphalt concrete increased after adding steel slag, which resulted in slower temperature rising speed. It was also found that, because of the different induction heating efficiencies of above three materials, the temperature difference of different asphalt concretes became more obvious with time increasing. Higher specific heat can result in slower energy exchange and lower temperature loss, which improve the induction healing rate of asphalt concrete. Therefore, it is harmful to pursue the exorbitant induction heating efficiency, and the heat storage performance of asphalt concrete should also be considered, because too low thermal storage performance and too high induction heating efficiency will cause asphalt concrete to experience more serious thermal expansion. It is more scientific to study the induction heating ability of asphalt concrete on the premise of considering its temperature storage ability.

3.3. Fracture Resistances. Figure 12 shows the variation tendency of $F_{0}$ of different asphalt concretes. From BA to FA and GSA to FGSA, $F_{0}$ increased obviously, resulting from toughening effect of steel fiber. The strength of asphalt concrete with steel fiber is composed of the cohesion of asphalt, the intercalation force between aggregate and aggregate, the tensile stress of fiber, and the adsorption force between fiber and asphalt. The overall strength of asphalt concrete depends on the performance of asphalt, properties of aggregates, and steel fiber. As shown in Figure 13, when ordinary asphalt concrete is subjected to tensile stress, the strength is mainly borne by the cohesion between asphalt. Because asphalt has poor effect of resisting external force, the tensile strength of ordinary asphalt concrete is low. A sudden brittle failure occurs when the ultimate tensile stress is reached. After the addition of steel fiber, the tensile stress is supported by the cohesion of asphalt and the force between asphalt and steel fiber. When asphalt concrete is subjected to force, the cohesion of asphalt first disappears and then relies on the adhesion between asphalt and steel fiber. The tensile stress is transferred to the contact surface of the asphalt and steel fibers, and the tensile strength of the asphalt concrete increases with the addition of fiber because of the enhanced bond between the asphalt and the fiber. From FA to FSA and other asphalt concretes with steel slag, $F_{0}$ dropped dramatically. This is contrary to our previous study [4]. Steel slag shows weak alkalinity due to the presence of metal oxides, which is more conducive to the adhesion to asphalt. This should lead to higher fracture strength. In the previous study, after the steel slag replacing the traditional aggregate, the bitumen-aggregate ratio increased, because the porous structure of the steel slag would need more asphalt binders. Therefore, sufficient asphalt can be combined with steel slag 


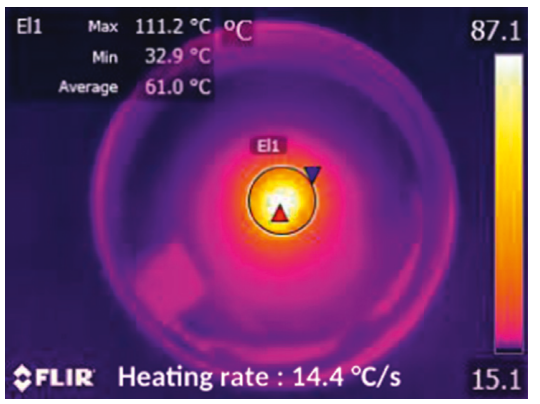

(a)

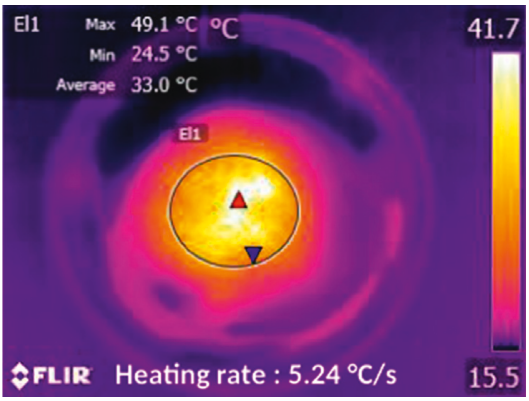

(b)

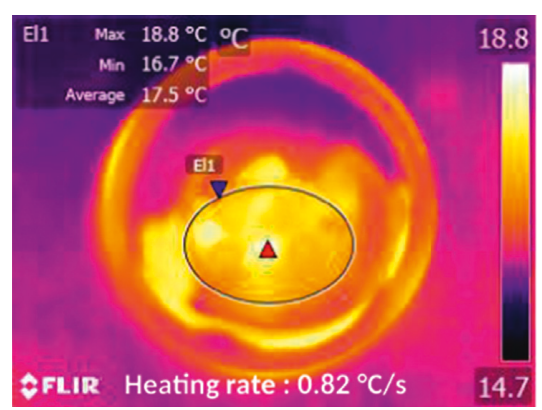

(c)

Figure 9: Infrared images of steel fiber (a), steel grit (b), and steel slag (c).

TABLE 5: Main chemical elements and oxides of steel slag.

\begin{tabular}{lcccccccccc}
\hline \multirow{2}{*}{ Element (Wt.\%) } & $\mathrm{Si}$ & $\mathrm{Fe}$ & $\mathrm{Al}$ & $\mathrm{Ca}$ & $\mathrm{Mg}$ & $\mathrm{Na}$ & $\mathrm{Ti}$ & $\mathrm{K}$ & $\mathrm{Px}$ & $\mathrm{Mn}$ \\
& 16.85 & 11.11 & 5.76 & 7.75 & 5.17 & 1.69 & 0.858 & 0.442 & 0.164 & 0.202 \\
\hline \multirow{2}{*}{ Oxide (Wt.\%) } & $\mathrm{SiO}_{2}$ & $\mathrm{Fe}_{2} \mathrm{O}_{3}$ & $\mathrm{Al}_{2} \mathrm{O}_{3}$ & $\mathrm{CaO}$ & $\mathrm{MgO}$ & $\mathrm{Na}_{2} \mathrm{O}$ & $\mathrm{TiO}_{2}$ & $\mathrm{~K}_{2} \mathrm{O}$ & $\mathrm{P}_{2} \mathrm{O}_{5}$ & $\mathrm{MnO}_{2}$ \\
& 36.04 & 15.89 & 10.89 & 10.84 & 8.58 & 2.28 & 1.43 & 0.532 & 0.376 & 0.260 \\
\hline
\end{tabular}

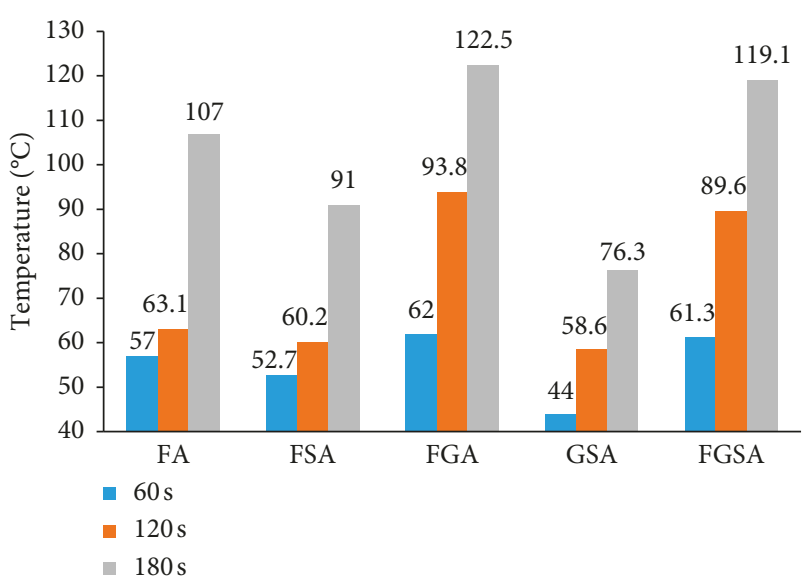

FIGURE 10: Induction heating temperature of asphalt concretes after different induction heating times.

to provide adhesion force. Unfortunately, in this study, in order to control the influencing factors, the bitumenaggregate ratio was the same for each kind of asphalt concrete, so the asphalt binder of asphalt concrete with steel slag was insufficient, and the fracture strength was affected. Nevertheless, after a reasonable design of the bitumenaggregate ratio of steel slag asphalt concrete, the steel slag still has a good application prospect in induction healing asphalt concrete because of promoting effect on improving healing rate. Overall, the addition of steel grit had a negative effect on the strength of asphalt concretes. This may be due to the shape and surface properties of the steel grit, which was not conducive to become stronger adhesion with asphalt, and the smooth surface also had a negative effect compared to steel fiber. As shown in Figure 14, the surface of the steel fiber was not a completely smooth structure after magnifying the steel fiber 50 times taken by optical microscope (BXF-150). It could be seen that there were more textures on the surface of steel fiber, and the existence of the texture enhanced the adhesion between the asphalt and the steel fiber. Thus, the shear stress was increased at the interface. When the stress acting on the interface was greater than the shear strength between the two interfaces, the fiber was gradually pulled out and destroyed, which did not happen on steel grit.

3.4. Induction Healing Rate. Figure 15 shows the healing rates of asphalt concretes doped with different conductive additives. Firstly, although the fracture resistances of the samples with steel slag were relatively low, when they were heated to $85^{\circ} \mathrm{C}$, the healing rates were high, of which FSA was the highest. The defective bitumen-aggregate ratio led to the decrease of fracture resistance, but the better heat preservation property of steel slag led to a better healing rate of asphalt concretes. In this study, the excellent performance of steel slag was firstly combined with electromagnetic induction heating, which may provide a new direction for the utilization of steel slag. In addition, the steel fiber not only gave the asphalt concrete better healing rate but also improved its fracture resistance. However, the performance of steel grit was unsatisfactory.

\section{Conclusions}

In this research, the induction heating and healing behaviors of asphalt concretes doped with different conductive additives were investigated. Based on the results discussed above, the following conclusions could be drawn:

(1) The addition of steel fiber and steel grit made asphalt concretes obtain better thermal conductivity, and the addition of steel slag improved the heat storage performance of asphalt concretes, which was beneficial to induction healing.

(2) Steel fiber had the best induction heating properties, and its induction heating temperature was $93.8^{\circ} \mathrm{C}$ 


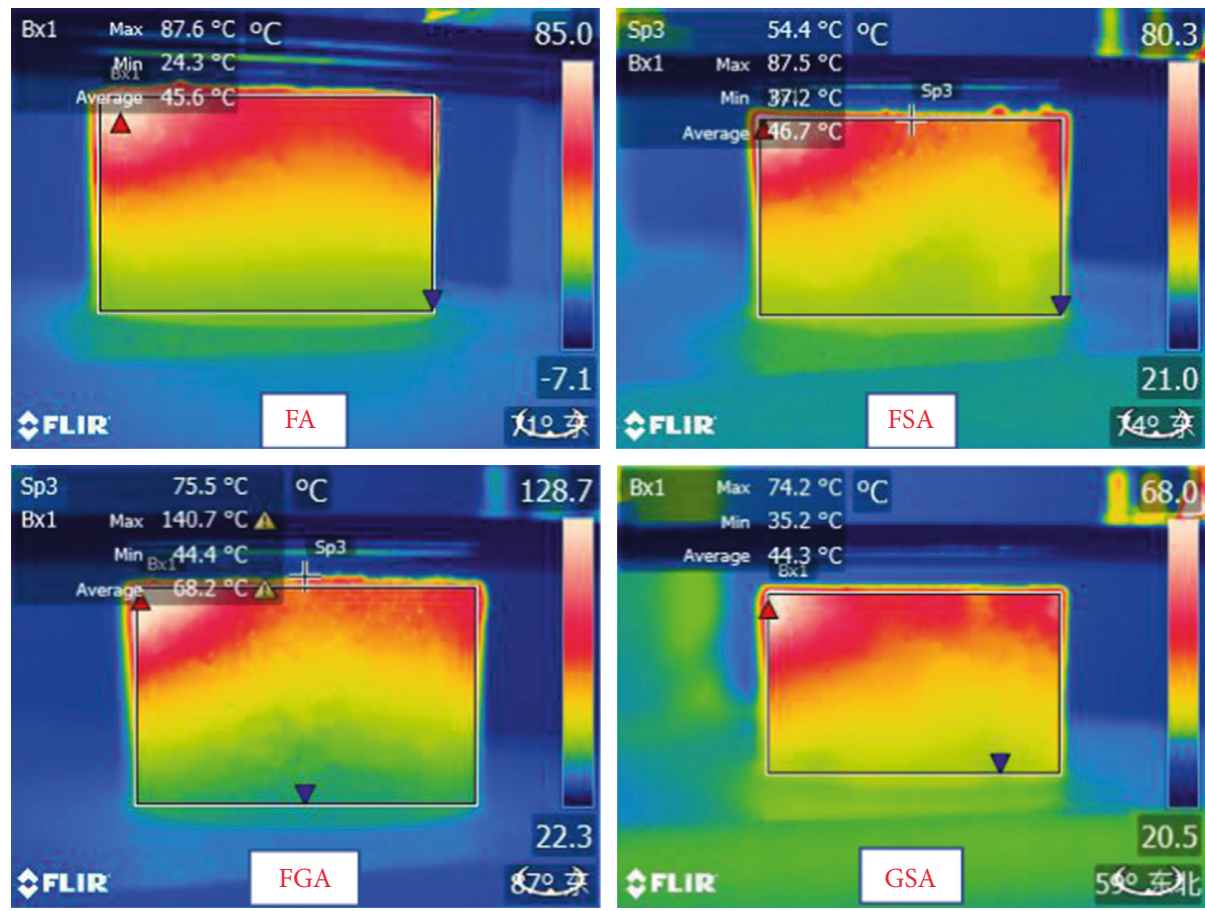

FIGURE 11: Induction heating infrared images of different asphalt concretes after $120 \mathrm{~s}$.

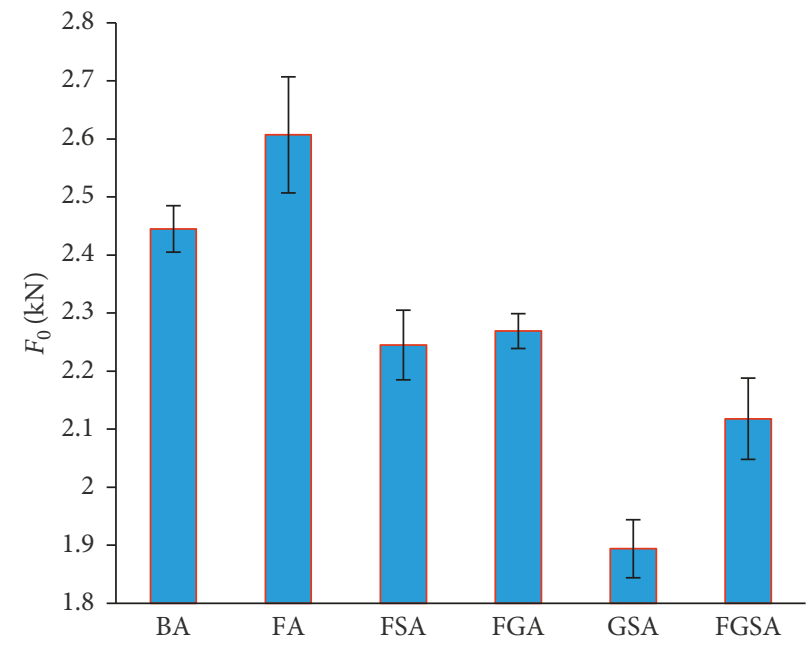

FIGURE 12: Fracture resistance of different asphalt concretes.

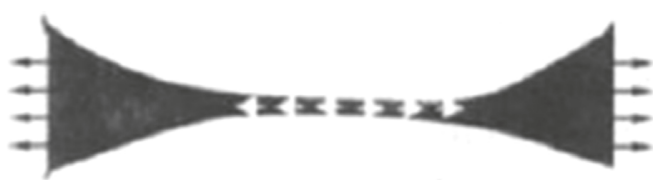

(a)

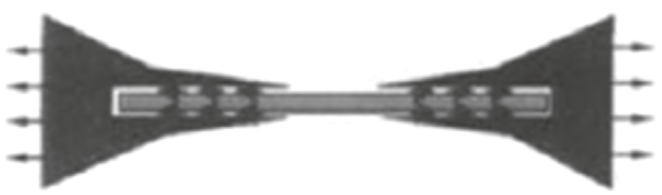

(b)

FIGURE 13: Failure mechanism of asphalt concrete: without steel fiber (a) and with steel fiber (b).

after $120 \mathrm{~s}$, the idea of replacing aggregate with steel grit in order to achieve better induction heating efficiency was not very successful, and steel slag had extremely weak induction heating ability due to the lack of elements or oxides that can be induction heating. 


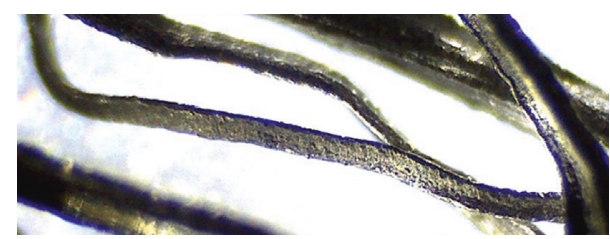

FIgURE 14: Surface texture of steel fiber.

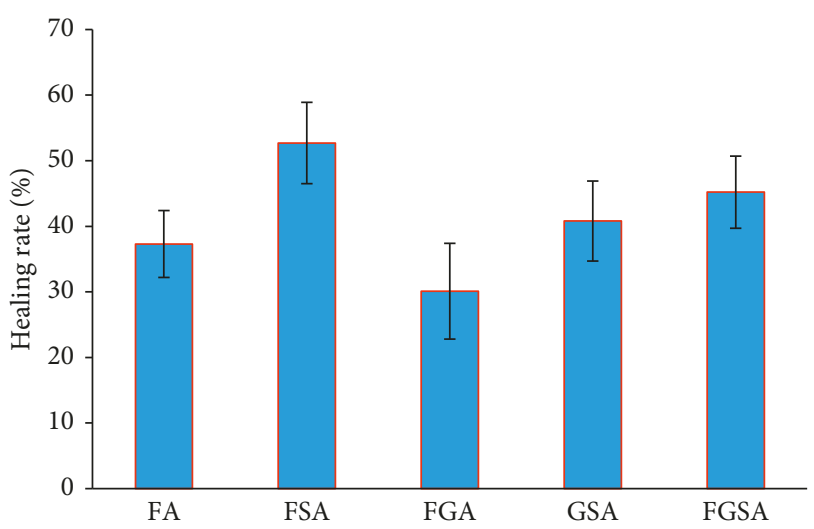

FIGURE 15: Healing rate of different asphalt concretes.

(3) Although the insufficient bitumen content lowered the mechanical strength of asphalt concretes with steel slag, its better thermal insulation property resulted in higher induction healing rate.

(4) It was suggested to adding steel slag to induction healing asphalt concrete.

\section{Future Researches}

The pavement performance of asphalt concretes needs to be evaluated and tested, such as high temperature rutting performance test, low temperature cracking performance test, fatigue performance test, water damage performance test, and freeze-thaw cycle test. More types of steel slag need to be evaluated to determine a new index on the application of steel slag in induction healing asphalt concrete.

\section{Data Availability}

The data used to support the findings of this study are available from the corresponding author upon request.

\section{Conflicts of Interest}

The authors declare that they have no conflicts of interest.

\section{Acknowledgments}

This research was funded by National Key R\&D Program of China (no. 2017YFE0111600) and National Natural Science Foundation of China (nos. 51778515 and 51508433).

\section{References}

[1] Z. Chen, S. Wu, Y. Xiao, W. Zeng, M. Yi, and J. Wan, "Effect of hydration and silicone resin on Basic Oxygen Furnace slag and its asphalt mixture," Journal of Cleaner Production, vol. 112, pp. 392-400, 2016.

[2] P. Pan, S. Wu, Y. Xiao, and G. Liu, "A review on hydronic asphalt pavement for energy harvesting and snow melting," Renewable and Sustainable Energy Reviews, vol. 48, pp. 624634, 2015.

[3] P. Q. Cui, S. P. Wu, Y. Xiao, M. Wan, and P. D. Cui, "Inhibiting effect of layered double hydroxides on the emissions of volatile organic compounds from bituminous materials," Journal of Cleaner Production, vol. 108, pp. 987991, 2015.

[4] Q. Liu, C. Chen, B. Li et al., "Heating characteristics and induced healing efficiencies of asphalt mixture via induction and microwave heating," Materials, vol. 11, no. 6, 2018.

[5] H. Li, J. Yu, S. Wu, L. Pang, Y. Li, and Y. Wu, "Property of anti-ultraviolet aging of LDHs modified asphalt," Journal of Wuhan University of Technology-Mater. Sci. Ed., vol. 33, no. 3, pp. 634-638, 2018.

[6] W. Zeng, S. Wu, J. Wen, and Z. Chen, "The temperature effects in aging index of asphalt during UV aging process," Construction and Building Materials, vol. 93, pp. 1125-1131, 2015.

[7] A. Chen, K. Şamlioglu, S. Tayfur, and H. Özen, "Effects of various additives on the moisture damage sensitivity of asphalt mixtures," Construction and Building Materials, vol. 19, no. 1, pp. 11-18, 2005.

[8] Y. Özen, S. Wu, Y. Dai et al., "Investigation of sodium stearate organically modified LDHs effect on the anti aging properties of asphalt binder," Construction and Building Materials, vol. 172, pp. 509-518, 2018.

[9] F. F. Chen and X. M. Huang, "Analysis of the mechanical response of rigid base asphalt pavement under heavy load," Journal of Highway \& Transportation Research \& Development, vol. 6, 2007.

[10] T. Li, "Study on influence of mineral aggregate gradations and spatial distribution on performance of asphalt mixture," Advanced Materials Research, vol. 586, pp. 191-198, 2012.

[11] T. You, R. K. A. Al-Rub, E. A. Masad et al., "Threedimensional microstructural modeling framework for dense-graded asphalt concrete using a coupled viscoelastic, viscoplastic, and viscodamage model," Journal of Materials in Civil Engineering, vol. 26, no. 4, pp. 607-621, 2013.

[12] Á. García, E. Schlangen, M. van de Ven, and Q. Liu, "A simple model to define induction heating in asphalt mastic," Construction and Building Materials, vol. 31, pp. 38-46, 2012.

[13] A. García, M. Bueno, J. Norambuena-Contreras, and M. N. Partl, "Induction healing of dense asphalt concrete," Construction and Building Materials, vol. 49, pp. 1-7, 2013.

[14] D. Partl, B. Li, F. Ye et al., "Fatigue behavior of microcapsuleinduced self-healing asphalt concrete," Journal of Cleaner Production, vol. 188, pp. 466-476, 2018.

[15] Q. Liu, Á. García, E. Schlangen, and M. v. d. Ven, "Induction healing of asphalt mastic and porous asphalt concrete," Construction and Building Materials, vol. 25, no. 9, pp. 3746-3752, 2011.

[16] Q. Ven, W. Yu, E. Schlangen, and G. van Bochove, "Unravelling porous asphalt concrete with induction heating," Construction and Building Materials, vol. 71, no. 71, pp. 152-157, 2014. 
[17] A. van Bochove, A. Garcia, M. N. Partl, G. Tebaldi, and P. Schuetz, "Induction healing of fatigue damage in asphalt test samples," Construction and Building Materials, vol. 74, pp. 162-168, 2015.

[18] A. S. Reddy, R. K. Pradhan, and S. Chandra, "Utilization of Basic Oxygen Furnace (BOF) slag in the production of a hydraulic cement binder," International Journal of Mineral Processing, vol. 79, no. 2, pp. 98-105, 2006.

[19] G. Wang, Y. Wang, and Z. Gao, "Use of steel slag as a granular material: volume expansion prediction and usability criteria," Journal of Hazardous Materials, vol. 184, no. 1-3, pp. 555-560, 2010.

[20] H. Alanyali, L. M., M. Çöl, and Ş. Karagöz, "Concrete produced by steel-making slag (basic oxygen furnace) addition in portland cement," International Journal of Applied Ceramic Technology, vol. 6, no. 6, pp. 736-748, 2009.

[21] Y. Karagöz, H. Hou, and S. Zhu, "Characteristics and mechanisms of phosphate adsorption onto basic oxygen furnace slag," Journal of Hazardous Materials, vol. 162, no. 23, pp. 973-980, 2009.

[22] Y. Xue, H. Hou, and S. Zhu, "Competitive adsorption of copper(II), cadmium(II), lead(II) and zinc(II) onto basic oxygen furnace slag," Journal of Hazardous Materials, vol. 162, no. 1, pp. 391-401, 2009.

[23] P. Ahmedzade and B. Sengoz, "Evaluation of steel slag coarse aggregate in hot mix asphalt concrete," Journal of Hazardous Materials, vol. 165, no. 1-3, pp. 300-305, 2009.

[24] Y. Sun, S. Wu, Q. Liu, J. Hu, Y. Yuan, and Q. Ye, "Snow and ice melting properties of self-healing asphalt mixtures with induction heating and microwave heating," Applied Thermal Engineering, vol. 129, pp. 871-883, 2018.

[25] Highway Science Research Institute, Ministry of Communications, Road Engineering Aggregate Test Code, China Communication Press, Beijing, China, 1994.

[26] Q. Liu, E. Schlangen, M. van de Ven, G. van Bochove, and J. van Montfort, "Evaluation of the induction healing effect of porous asphalt concrete through four point bending fatigue test," Construction and Building Materials, vol. 29, pp. 403409, 2012.

[27] Á. García, "Self-healing of open cracks in asphalt mastic," Fuel, vol. 93, no. 1, pp. 264-272, 2011.

[28] J. Wan, S. Wu, Y. Xiao, Z. Chen, and D. Zhang, "Study on the effective composition of steel slag for asphalt mixture induction heating purpose," Construction and Building Materials, vol. 178, pp. 542-550, 2018. 


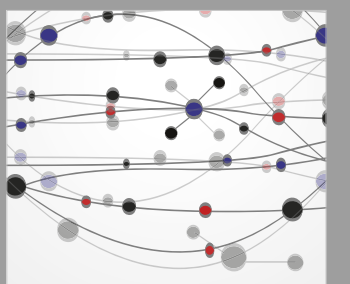

The Scientific World Journal
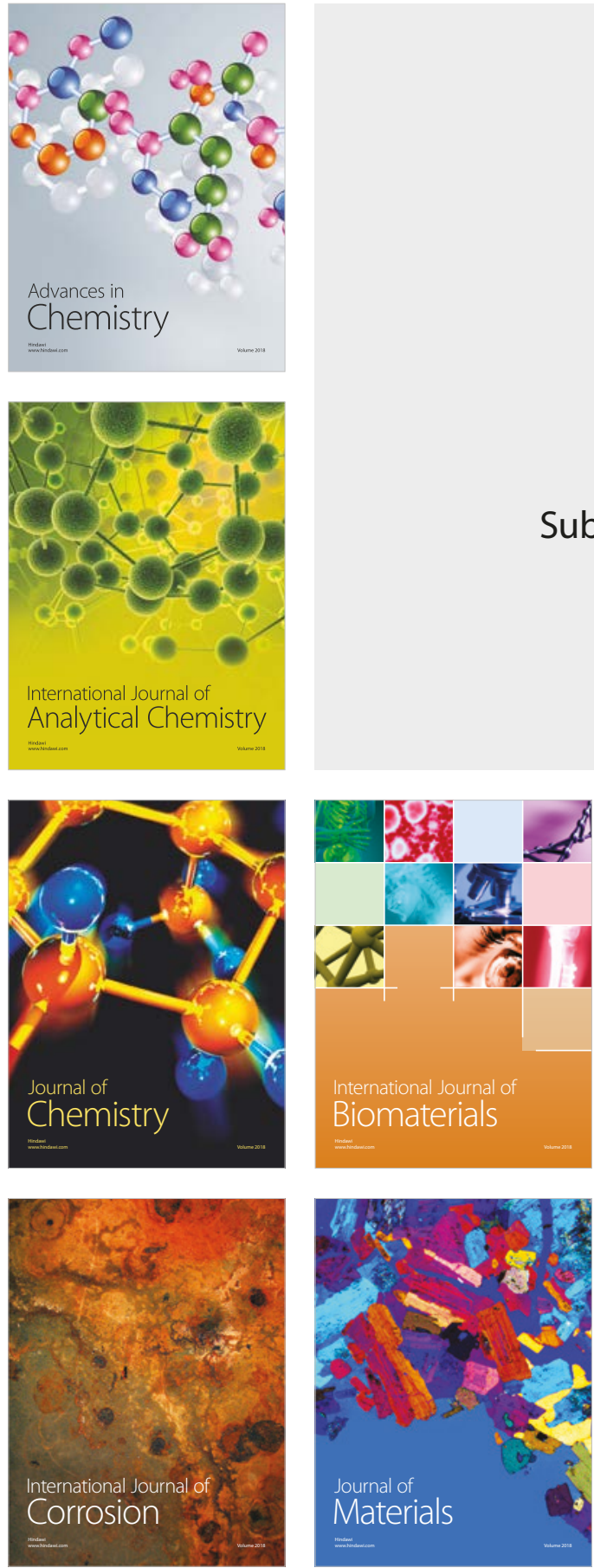

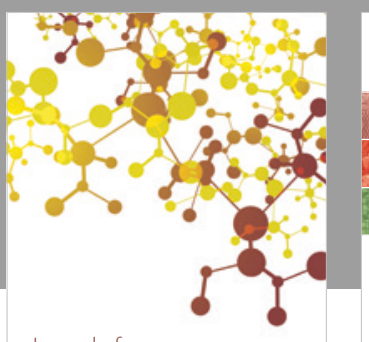

Journal of

Applied Chemistry
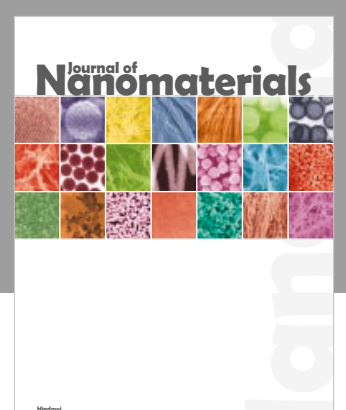

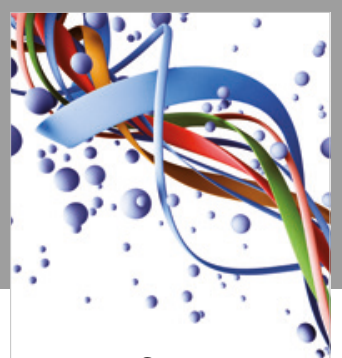

Scientifica

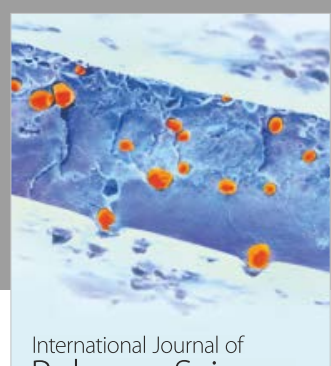

Polymer Science

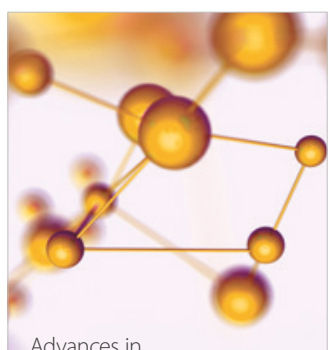

Physical Chemistry
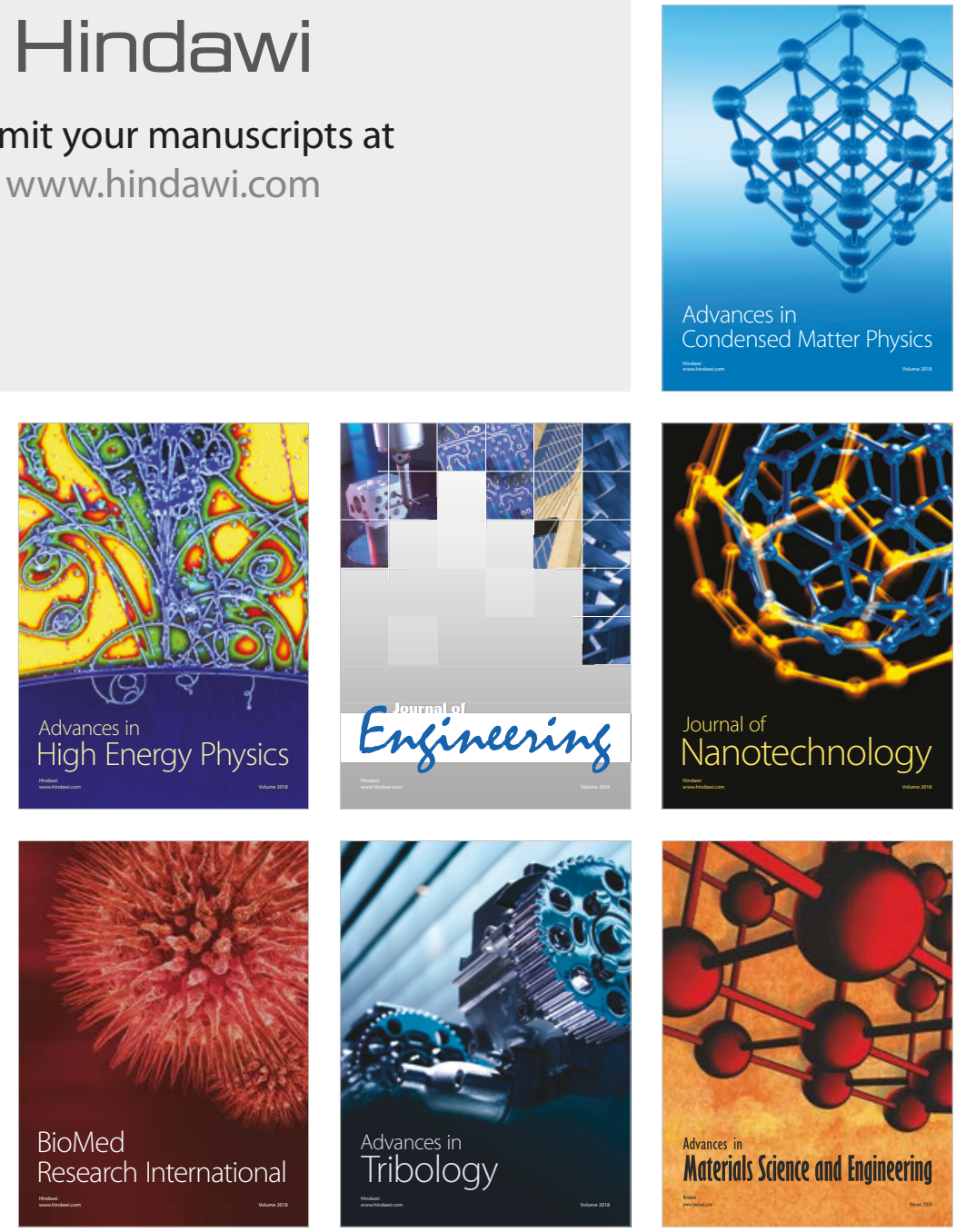